\title{
输煤栈桥钢桁架的加固研究
}

金松

中煤科工集团沈阳设计研究院有限公司

DOI:10.32629/btr.v2i3.1972

[摘 要] 钢桁架栈桥广泛应用在煤炭矿井、洗煤厂及大型电厂等工程中, 由于设计、施工和使用管理不当,材料缺陷或遭受灾 害, 以及使用功能改变等情况, 需要对其进行加固设计。本文归纳总结了钢结构常见都加固原因和加固方法, 对西湾露天矿破碎 间至混煤仓栈桥下撑式钢析架出现局部震动、下撑杆节点板断裂问题,进行加固设计。

[关键词] 加固原因; 加固方法; 下撑杆震动加固；断裂节点板加固

钢结构具有材料强度高、质量轻、抗震性能好、造型美 观、施工标准化高等优点, 其作为朝阳产业, 近年来的发展和 应用突飞猛进。伴随着钢结构建筑数量的增长, 钢结构也逐 渐暴露了一些问题和安全隐患。对问题建筑不能盲目的拆除 重建, 那么如何采取有效措施对其进行加固处理, 是众多工 程人员要面临解决的重要问题。

\section{1 钢结构加固技术现状}

1.1 在日常使用中, 其会随着时间的推移发生损伤, 其力 学性能以及承载能力大大降低, 严重的甚至发生倒塌的可能, 导致需要进行加固改造的常见原因如下:

1. 1.1 由于钢结构所承受的荷载发生较大的变化, 导致 其超过使用年限, 构件损伤致使钢结构的承载力不足;

1.1.2 钢结构经过长期的使用会产生不同程度的变形、 锈蚀、扭曲、伤残、凹陷等现象, 杆件尧曲, 连接开裂等使结 构构件截面严重削弱;

1.1 .3 火灾、雪灾等自然灾害引起的温差变化会使构件 或连接杆件产生变形、开裂和趐曲;

1.1.4 使用的钢材质量不符合要求;

1.1.5 化学和电化学等对钢材的腐蚀作用会削弱钢构件 的截面;

1.1.6 其他包括设计、生产、施工中的人为因素所导致 的失误以及使用期间对结构的违规使用和操作。

1.2 分析钢结构加固改造的常见原因, 研究钢结构加固 领域的现状, 经过梳理总结, 按不同的分类方式钢结构分为 不同的加固方法:

1.2.1 按加固对象划分

钢结构加固按加固的对象或部位不同, 可以分为钢柱的 加固、钢梁的加固、钢屋架或析架的加固、吊车系统的加固、 连接和节点的加固、裂纹的修复和加固。

\subsection{2 按损害或加固范围划分}

钢结构加固按损害或加固范围划分为全面加固和局部 加固, 局部加固可以进一步分为增加杆件截面法、减小杆件 自由长度法、连接节点加固法。

1.2 .3 按设计方法划分

钢结构加固按设计方法不同分为改变计算简图法和不
改变计算简图法, 不改变计算简图法又称为增大截面法, 改 变计算简图法进一步分为改变荷载分布状况、改变传力途 径、改变节点性质、改变边界条件、增设附加杆件或支撑、 施加预应力、考虑空间协同作用等。

\subsection{4 按施工方式划分}

钢结构加固按施工方式可以分为负载加固和卸载或部 分卸载加固。

\section{2 .5 按加固材料}

钢结构加固按加固材料的不同, 可以分为粘贴钢板加固 法 (粘钢加固) 和粘贴纤维增强复合材料 (FRP) , 其中常用的 FRP 有碳纤维增强复合材料 (CFRP)、玻璃纤维增强复合材料 (GFRP) 和芳纶纤维增强复合材料 (AFRP)。

\section{2 工程实例概况}

本文以实际工程为例, 研究钢结构加固方法。陕西神延 煤炭有限责任公司西湾露天煤矿生产系统已于 2016 年建成 并投产运行。在日常巡检过程中发现篮分破碎间至混煤仓栈 桥的第 8 榀钢桁架出现以下情况:

2.1 第 8 榀钢桁架下撑杆有明显震动, 震动部位见图 1 所示:

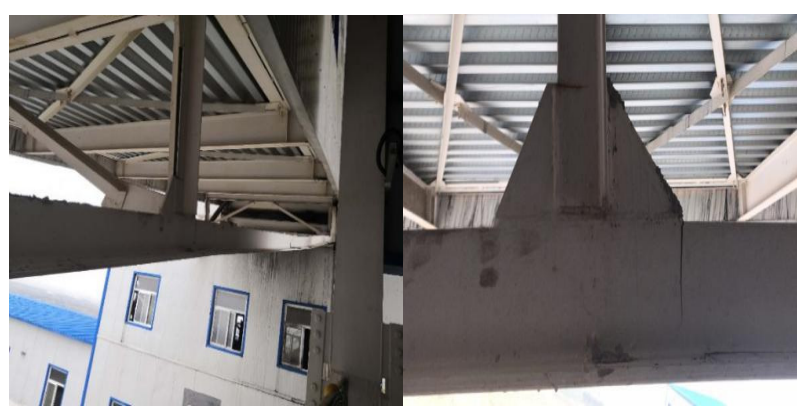

图 1 下撑杆震动部位 图 2 节点板断裂部位

2.2 第 8 榀钢桁架下撑处节点板发生断裂, 断裂部位见 图 2 所示:

对于西湾篮分破碎间至混煤仓栈桥, 由于栈桥施工季节 为冬季 (西湾煤矿位于严寒地区), 室外施工温度很低, 焊接 部位易出现较大的拉应力和焊接残余应力, 从而产生应力集 中; 由于下撑杆与皮带滚轴产生共振效应, 即相当于产生应 
力幅很小的连续重复荷载。因此在应力集中和震动的共同作 用下, 结构杆件在焊接部位出现裂缝, 使得结构构件截面削 弱, 钢结构的承载力不足。

本文通过钢结构加固技术的分析, 解决西湾篮分破碎间 至混煤仓栈桥钢桁架出现的问题，进行钢桁架加固设计。

\section{3 钢桁架加固设计}

通过对输煤栈桥桁架问题的分析研究, 考虑实际情况, 进行负载加固设计, 属于局部加固范畴, 其中增加杆件截面、 减小杆件自由长度、连接节点加固等均有涉及。

3.1 第 8 榀钢桁架下撑杆震动加固设计

第 8 榀钢桁架下撑计算长度为 4 倍的节间长度, 为了改变 下撑杆的自振频率, 可以在中间处增设 1 处坚杆, 减小钢桁架 下撑杆的计算长度为 2 倍的节间长度。其中, 增设坚向角钢减 小钢桁架平面内下撑杆的计算长度, 见图 3 侧视图; 增设水平 角钢减小钢桁架平面外下撑杆的计算长度, 见图 3 横断视图。

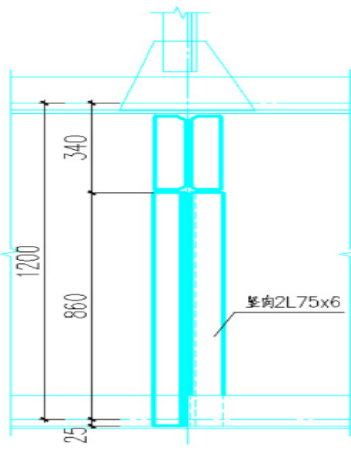

侧视图

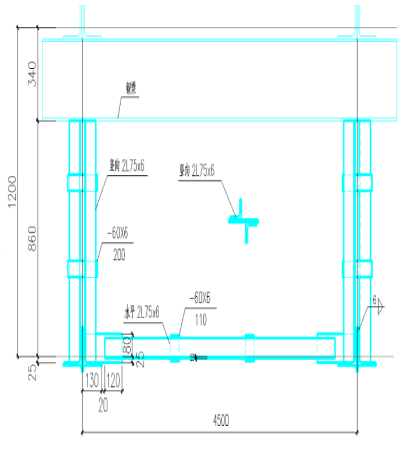

横断视图
图 3 节点板断裂部位

3.2 第 8 榀钢桁架下撑断裂节点板加固设计

第 8 榀钢桁架下撑节点板处有水平和坚向两处裂纹, 应分 别进行加固设计。水平裂纹处应对坚杆与节点板连接处进行 加固; 坚向裂纹处应对撑杆与节点板连接处加固, 如图 4 所示。

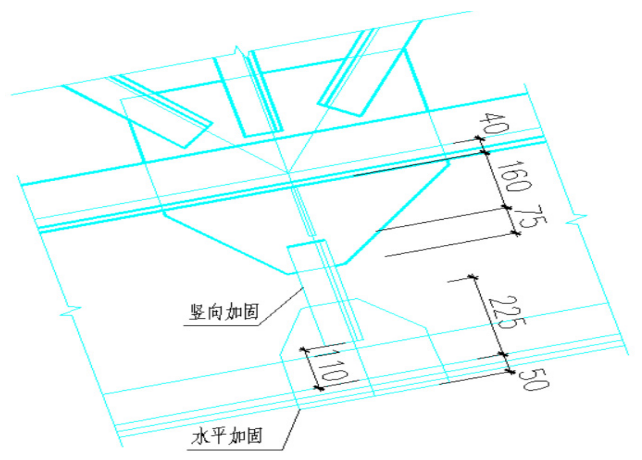

图 4 加固部位

a 水平裂纹加固

对坚杆与节点板连接处进行加固, 如图 5 所示:
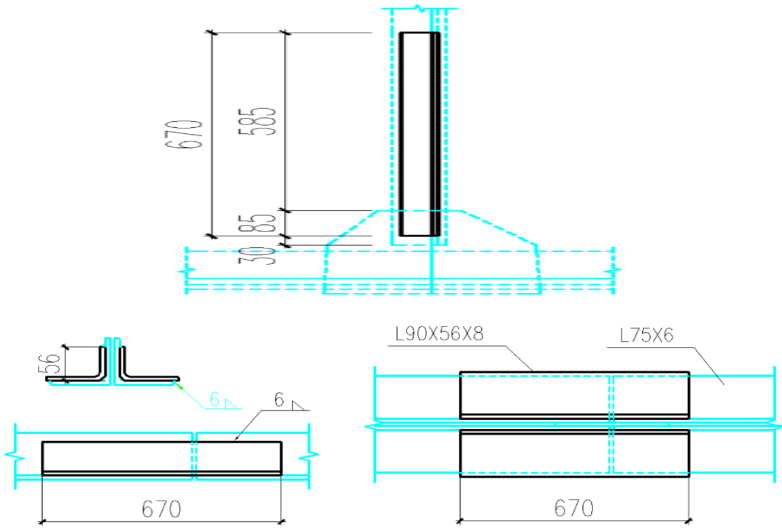

图 5 水平裂纹加固

b 坚向裂纹加固

对撑杆与节点板连接处进行加固, 如图 6 所示:

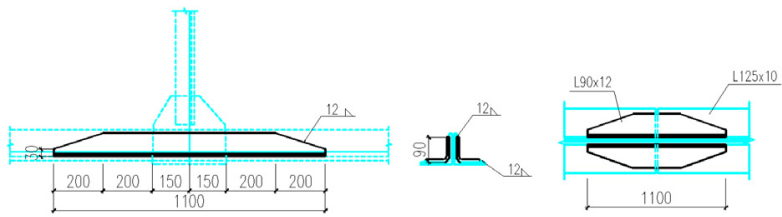

图 6 坚向裂纹加固

\section{4 结束语}

西湾笁分破碎间至混煤仓栈桥钢桁架经过加固处理后, 恢复正常使用, 反馈使用情况良好。

钢结构或钢构件的加固需要考虑许多因素, 最重要的就 是考虑选取何种加固形式, 其中需要权衡各相关因素, 如经 济条件、方便施工、加固需要满足提高的承载能力。虽然当 前钢结构加固研究已经取得了较大的成果, 实际应用过程中 积累了很多经验, 但在一些方面仍需要进行深入的研究。

4.1 重视设计时计算模型的假定, 务求多工况全面分析 研究, 符合实际情况。

4.2 重视施工工艺: 负载加固, 除设计加固钢构件满足 一定应力比条件外, 更要注重施工, 应该编制详实的施工组 织方案, 采取可靠的施工措施, 并组织专家进行论证。

4.3 建立对加固部位的应力应变监测体系, 保证加固后 的结构或构件能够安全使用。

[参考文献]

[1]尹否. 钢结构加固技术的探讨与研究 [J]. 建材世 界,2011(03):27.

[2]王天书.BIM 技术在门式刚架轻钢结构厂房加固中的 应用研究[D].安徽: 安徽建筑大学,2017(04):74.

[3]祝瑞祥.负载下钢结构构件增大截面加固设计方法对 比分析 [J].四川建筑科学研究,2014(2):98-103.

[4]蒋立.钢结构负载下焊接加固压弯构件研究 [D]. 重庆: 重庆大学,2015(16):63. 